\title{
Single phase online Uninterruptible power supply with unity power factor
}

\author{
Devika Hebbal ${ }^{1}$, Mr. Naveen $\mathbf{J}^{2}$ \\ PG Scholar, Electrical, NMAMIT, Nitte, India ${ }^{1}$ \\ Assistant Professor, Electrical, NMAMIT, Nitte, India
}

\begin{abstract}
A power factor of one is the main goal of any electric utility to have a better efficiency. Here, a single phase Uninterruptible power supply( UPS) is proposed which has a unity power factor for all linear and nonlinear loads. The proposed UPS uses an active PFC circuit to achieve unity power factor, a battery charger using Flyback converter, push pull converter is used as a battery discharger, a half bridge inverter for DC-AC conversion. Simulations are carried out for two conditions one for power factor variation in the mains and the other during power outage.Simulations are done using MATLAB/Simulink.
\end{abstract}

Keywords: UPS,Active PFC circuit, Flyback converter, Push Pull converter, half bridge inverter.

\section{INTRODUCTION}

Uninterruptible power supplies are designed to have continuous power supply even during the conditions of power outage.UPS are of the following types, offline UPS, and online UPS .Offline UPS is also called as passive standby UPS, online UPS has two kinds-line interactive and double conversion UPS. Here a double conversion UPS is proposed which is capable of delivering a regulated sinusoidal output voltage with low total harmonic distortion and a unity power factor for linear and nonlinear loads. The advantages of using a double conversion UPS is that they are very tolerant to variations in the supply voltage and their output is highly regulated. Also, there is no delay between normal operation and inverter operation. But the main disadvantage of double conversion UPS is it has very low power factor and low efficiency. Because the input rectifier changes the shape of input current waveform. Hence a PFC circuit has to be added to improve the power factor. Double conversion UPS comprises of a rectifier for AC-DC conversion, a battery charging circuit an inverter and a bypass switch/static switch .Here the inverter always supplies the load during normal as well as inverter operation. Hence its power rating should fulfil $100 \%$ of the power demanded to charge the battery banks and also to meet the load requirement.

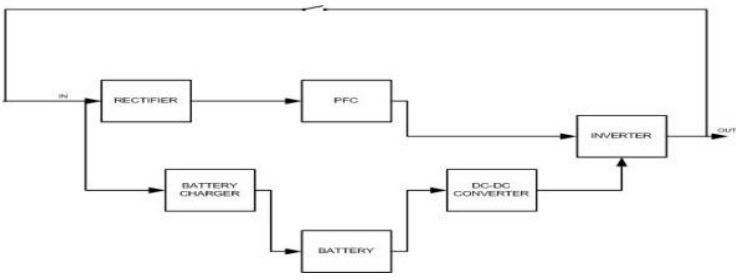

Fig. 1 Single phase online double conversion UPS
The fig 1 shows the online double conversion UPS and it consists of rectifier, PFC circuit. A battery charger, a battery set, a DC-DC converter, an inverter a bypass switch.

\section{PROPOSED SYSTEM}

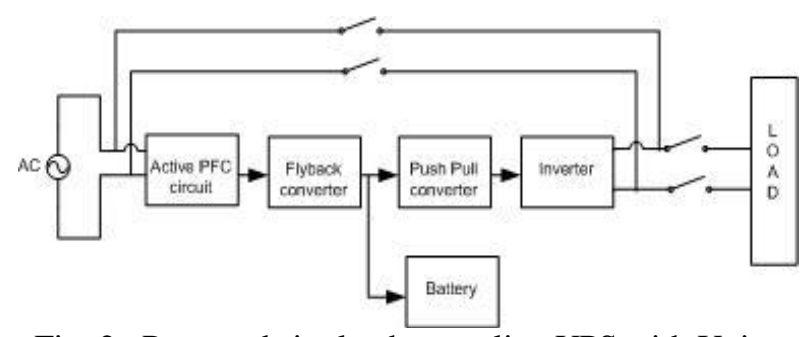

Fig. 2. Proposed single phase online UPS with Unity power factor

The above model shown is the proposed single phase UPS with unity power factor. It consists of a bridge rectifier with active PFC circuit. With the use of power electronics, the shape of current waveform drawn by the load can be changed, so that the power factor can be improved. This method is known as active power factor correction. Here, a boost converter is placed in between the bridge rectifier and input capacitors. This circuit will help to maintain a constant DC bus voltage at its output and draws the current in phase with the line voltage. The voltage and frequency should be same as the line voltage. This circuit will help to achieve unity power factor for all linear and nonlinear loads. A flyback converter is designed to charge a battery of $12 \mathrm{~V}$. The battery used is a lead acid battery. The push-pull converter is used to boost the voltage and to maintain the DC voltage constant at the input of the 
inverter, SPWM technique is used and an LC filter is A. SIMULATION OF VARIATION OF POWER FACTOR IN THE designed at the output of the inverter to get a pure MAINS

sinusoidal voltage.

\section{III.SIMULATIONS}

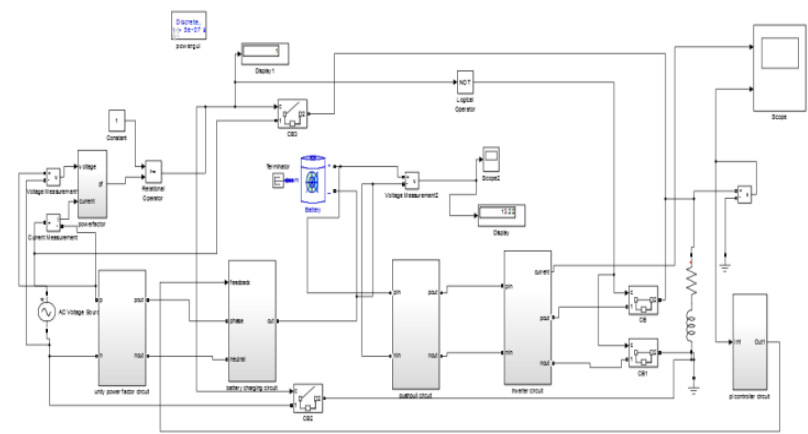

Fig. 3 Simulink model of single phase online UPS

The Fig 3 shows the simulink model of single phase UPS. Where the mains is supplying the load.Whenever the power factor of mains goes below 0.9 the UPS will supply the load .For any kind of load the UPS will have a unity power factor.

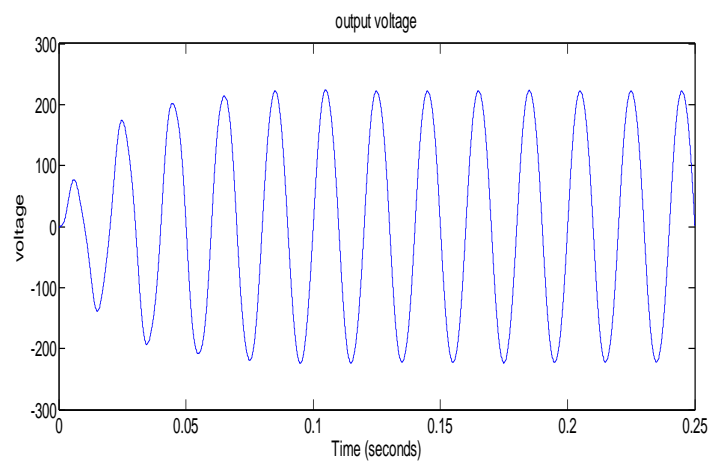

Fig. 4 Output voltage of mains

The fig 4 shows the output voltage of mains supplying the load. The Vrms is $230 \mathrm{~V}$ and is regulated sinusoidal output.

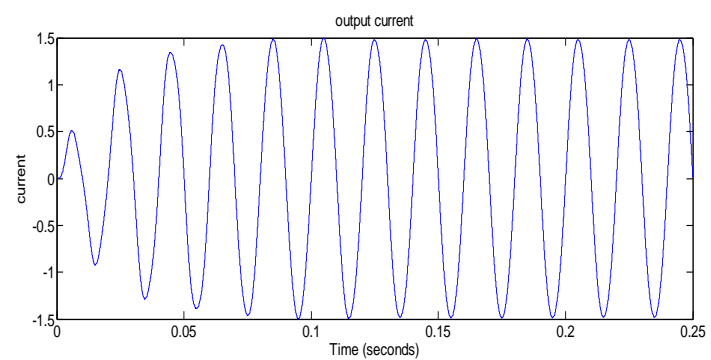

Fig. 5 Output current of mains

Fig 5 shows the output current of mains . The Irms is 1.5A. The mainw2s will supply the load when the power factor mains is 0.9 .
The Fig 6 shown below is the simulink model of power factor variation in the mains ie power factor goes below 0.9 and hence UPS supplying the load with unity power factor.

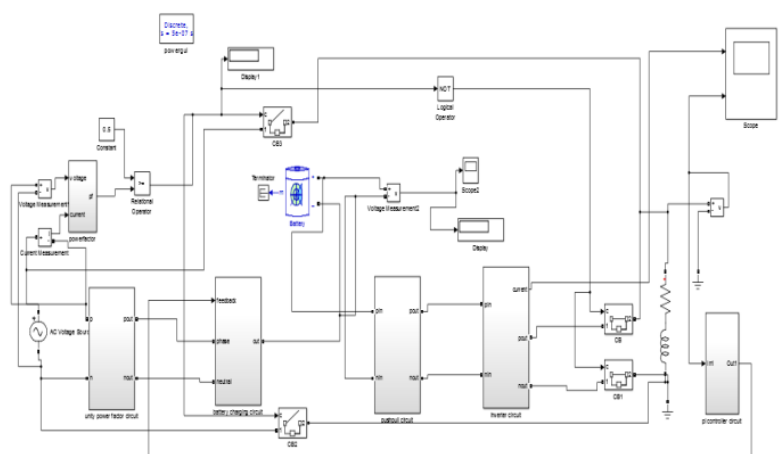

Fig .6 Simulink model of variation of power factor in UPS.

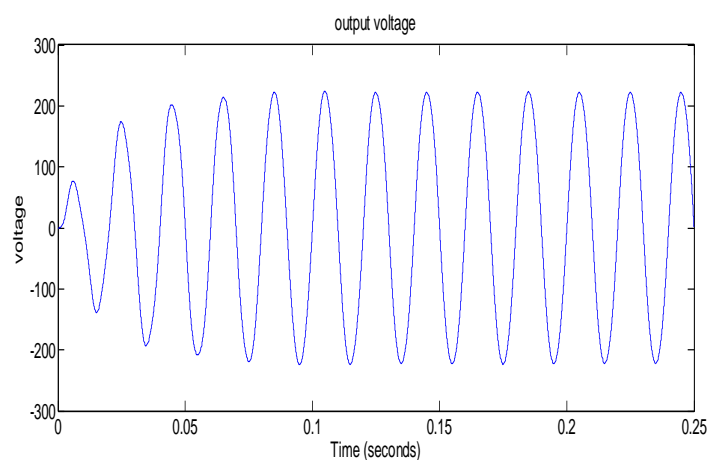

Fig. 7 Output voltage of UPS

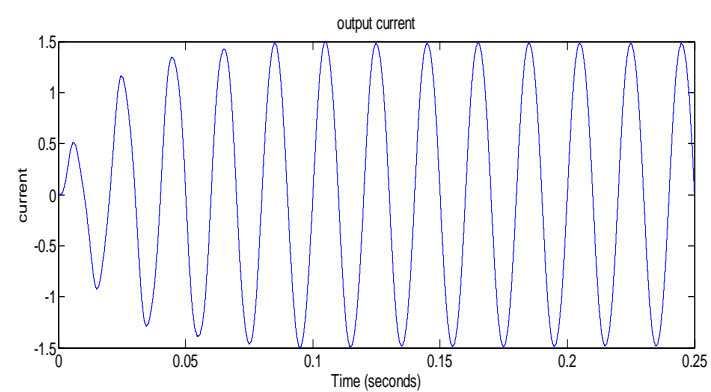

Fig. 8 Output current of UPS

Fig $7 \& 8$ show the simulation results of output voltage and output current of UPS supplying the load during power factor variation in the mains. The output voltage is a regulated sinusoidal waveform.

B. Simulation of mains supplying the load

Fig 9 shown below is the simulation of mains supplying the load. The load is being supplied by the mains, the output is a regulated 230 Vrms sinusoidal waveform. 


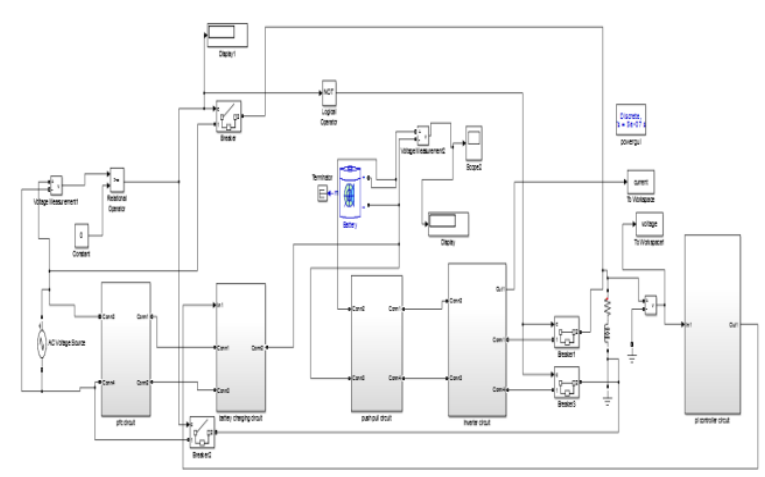

Fig. 9 Simulations of mains supplying the load

The above model shows the operation of mains .Here the inverter is off.A comparator is used to compare the voltage between the reference voltage and the mains voltage .If the voltage from the mains is $230 \mathrm{~V}$ then the mains switch will get closed and the inverter switch will get open .Hence the load is supplied by mains. The Results of output voltage and output current are as shown below.

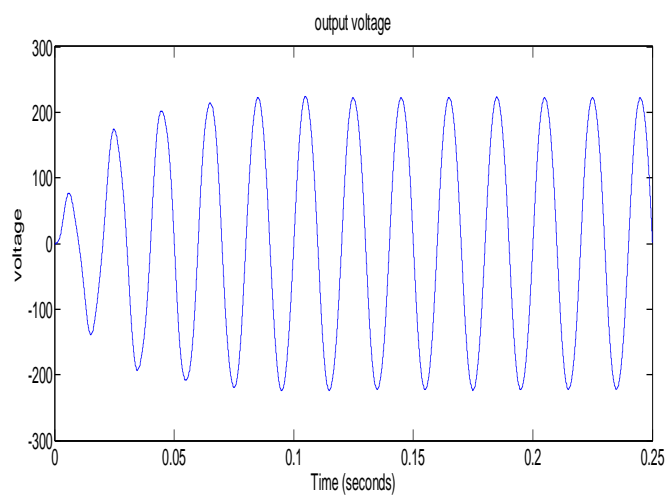

Fig. 10 Simulation results of output voltage of mains.

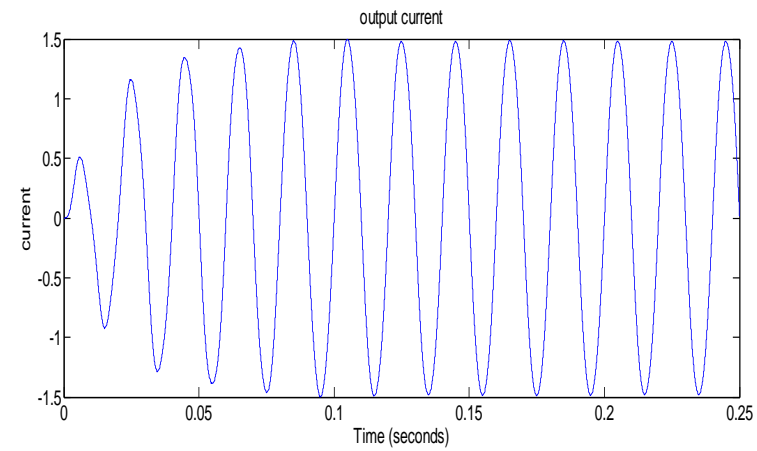

Fig. 11 Simulation results of output current of mains.

C. Simulations during power outage

The model shows the operation of UPS during power outage. Here a comparator is used to know the mains voltage and reference voltage. If the mains voltage is zero or during power outage the inverter switch closes and the mains switch closes .Hence the UPS will supply the load.

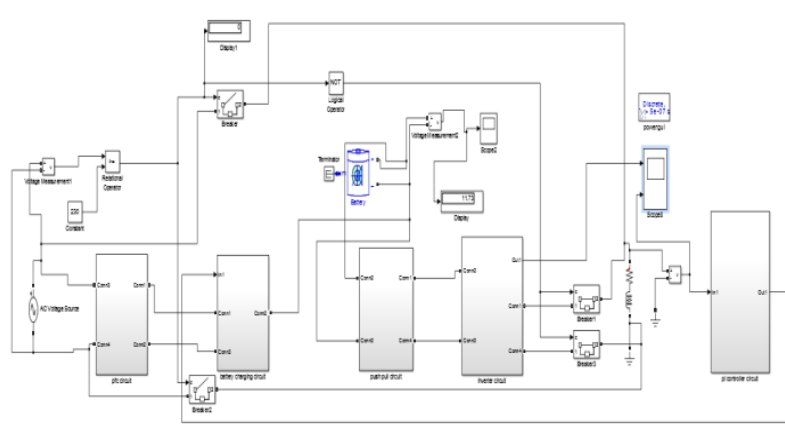

Fig. 12 UPS supplying load during power outage.

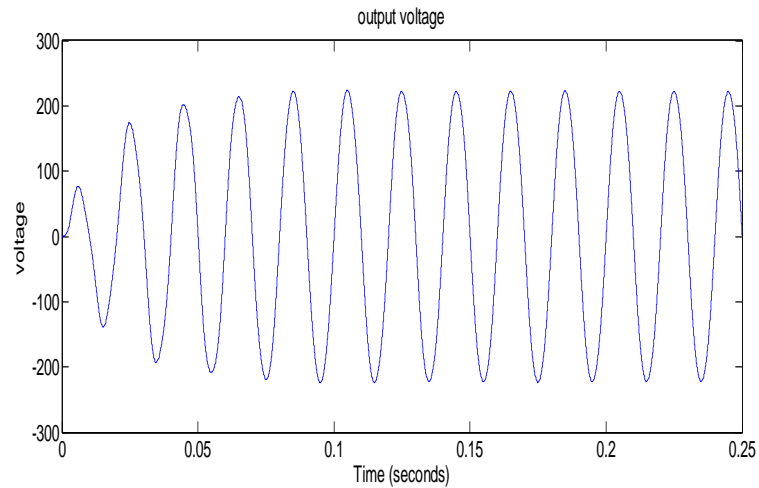

Fig. 13 Output voltage of UPS

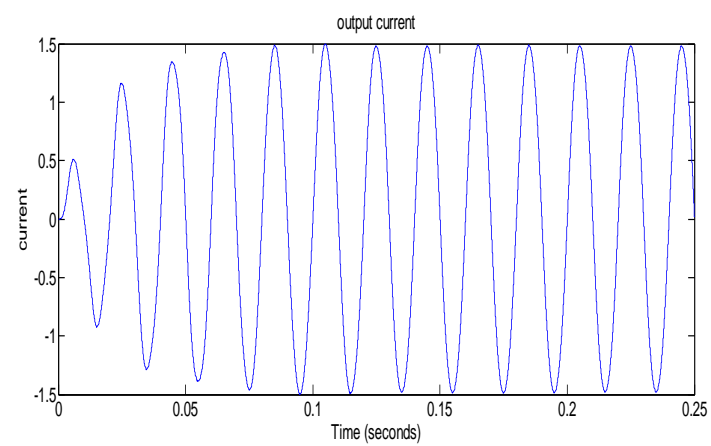

Fig. 14 Output current of UPS

Table I SYSTEM PARAMETERS

\begin{tabular}{|l|l|}
\hline Output frequency & $50 \mathrm{~Hz}$ \\
\hline Output voltage & $230 \mathrm{Vrms}$ \\
\hline De link voltage & $650 \mathrm{~V}$ \\
\hline Dc link capacitors & $4000 \mu \mathrm{F}$ \\
\hline Flyback converter & $\mathrm{Vs}=48 \mathrm{~V}, \mathrm{Vo}=12 \mathrm{~V}, \mathrm{D}=0.5, \mathrm{fs}=30 \mathrm{k}$ \\
\hline $\begin{array}{l}\text { Pushpull } \\
\text { converter }\end{array}$ & $\mathrm{Vs}=12 \mathrm{~V}, \mathrm{~V} 0=620 \mathrm{~V}, \mathrm{D}=0.5 . \mathrm{fs}=30 \mathrm{k}$ \\
\hline Switching device & Mosfet \\
\hline R-L load & $30 \Omega, 10 \mu \mathrm{H}$ \\
\hline Output LC filter & $5 \mathrm{mH}, 200 \mu \mathrm{F}$ \\
\hline $\begin{array}{c}\text { PFC switching } \\
\text { device }\end{array}$ & Mosfet, $\mathrm{fs}=10 \mathrm{k}$ \\
\hline
\end{tabular}




\section{IV.CONCLUSION}

In this paper a single phase online UPS with unity power factor is proposed. The proposed system is simulated using MATLAB/Simulink. The simulations are carried out for power factor variation in mains and power outage conditions, both the results are verified. The output voltage of single phase UPS is a pure regulated sine wave, and the UPS achieves unity power factor for all types of loads. Also there is no delay between normal operation and inverter operation.

\section{ACKNOWLDEMENT}

Authors gratefully acknowledge the support received from NMAM Institute of Technology, Nitte. Education Trust and VTU, Belagavi in carrying out the research work.

\section{REFERENCES}

[1] S. Karve, "Three of a kind UPS topologies, IEC standard," IEE Review, Vol. 46, No. 2, pp. 27-31, Mar. 2000.

[2] W. Solter, "A new international UPS classification by IEC 62040 3 ," in Proc. Internationarl Telecommunications Energy Conf., pp. $541-545,2002$.

[3] P. C. Loh, M. J. Newman, D. N. Zmood, and D. G. Holmes, "A comparative analysis of multi-loop voltage regulation strategies for single and three-phase UPS systems," IEEE Trans. Power Electron., Vol. 18, No. 5, pp. 1176-1185, Sep. 2003.

[4] T.-J. Liang and J.-L. Shyu "Improved DSP-controlled online UPS system with high real output power," IEE Proc.-Electr. Power Appl., Vol. 151, No. 1, January 2004.

[5] W. Zhang, G. Feng, Y.-F. Liu, and B. Wu, "A digital power factor correction (PFC) control strategy optimized for DSP," IEEE Trans. Power Electron., Vol. 6, No. 6, pp. 1474-1485, Nov. 2004

[6] S. B. Bekiarov and A. Emadi, "Uninterruptible power supplies: classification, operation, dynamics, and control," APEC 2002, Vol. 1, pp. 597-604, 2002

[7] IEEE Transactions on Industry Applications, VOL. IA-1 5, NO. 6 , November/December 1979, Optimum Filter Design for a SinglePhaseSolid-StateUPS SystemS. B. Dewan, senior member, IEEE. And p. D. Ziogas, member, IEEE

[8] Practical Control Implementation of a Three- to Single-Phase Online UPSEung-Ho Kim, Jung-Min Kwon, Student Member, IEEE, Jae-Kyu Park, and Bong-Hwan Kwon, Member, IEEE 